\title{
ВЛИЯНИЕ ЭКОНОМИКИ НА ЭКОЛОГИЮ КРАСНОЯРСКОГО КРАЯ
}

\author{
(c) 2019 Толстихина Екатерина Дмитриевна \\ студент магистратуры кафедры строительных материалов и технологий строительства \\ Сибирский федеральный университет, Россия, Красноярск \\ E-mail: tolstihina1006@yandex.ru \\ (c) 2019 Арабли Лариса Александровна \\ студент кафедры промышленного и гражданского строительства \\ Сибирский федеральный университет, Россия, Красноярск \\ E-mail: arabli838@mail.ru \\ (c) 2019 Зенкова Ульяна Владимировна \\ студент кафедры промышленного и гражданского строительства \\ Сибирский федеральный университет, Россия, Красноярск \\ E-mail: ulya.zenulya99@gmail.com \\ (c) 2019 Андронова Арина Евгеньевна \\ студент кафедры инженерных систем зданий и сооружений \\ Сибирский федеральный университет, Россия, Красноярск \\ E-mail: vip.andronova2000@mail.ru \\ (c) 2019 Гуро Дарья Тимуровна \\ студент кафедры экспертизы и управления недвижимостью \\ Сибирский федеральный университет, Россия, Красноярск \\ E-mail: gdt2180@gmail.com \\ (c) 2019 Миронова Александра Леонидовна \\ студент кафедры экспериментальной физики и инновационных технологий \\ Сибирский федеральный университет, Россия, Красноярск \\ E-mail: sasha235787@gmail.com
}

Вопрос экологии является одним из главных в современном мире. Для Красноярского края проблема «черного неба» остается нерешенной уже долгое время. Состояние окружающей среды ухудшается из-за выбросов предприятий и выхлопных газов автотранспорта. Целью данной статьи является анализ влияния экономики на экологию Красноярского края. Поднимаются вопросы о загрязнителях экологии края, влиянии ее на здоровье человека и пути решения её с помощью экономических структур.

Ключевые слова: Красноярский край; экология края; экономика; выбросы предприятий; выбросы в атмосферу; здоровье человека; офшор.

В Красноярском крае существует много промышленных предприятий: по производству цветной и черной металлургии, машиностроению, гидроэнергетике, добыче полезных ископаемых, нефтехимической и деревообрабатывающей промышленности. Большая часть из них за год выбрасывает в атмосферу до несколько тысяч тонн вредных веществ. Не секрет, что развитие производства в крае сильно ухудшает экологическую обстановку за счет увеличения разных видов выбросов в атмосферу.

Основной проблемой выбросов от предприя- тий является не количество и мощность, а именно технология производства (методы фильтрации и утилизации отходов).

Страна и в точности наш край в целом, использует последние плоды сырьевой экономики и не переходит на инновационную. А почему это происходит? Все экономические модели развиваются, имеют свое начало и конец. Такие модели, как и в технологиях, достаточно хорошо работают, их можно тестировать и предугадать, они приносят дополнительную прибыль. Например, можно ввести налоги на выбросы предпри- 
ятий, использовать эти деньги для озеленения территорий или же для установки фильтров.

К сожалению, наша экономика развивается по принципу «взял у природы, что захотел в любом и неограниченном количестве - использовал - выкинул». Конечно, это плохо сказывается и на самом человеке. Необходимо осознание потребности развития в рамках замкнутых циклов. Ведь человек не понимает, что каждым своим действием он делает плохо не только себе, но и всем своим окружающим и природе в целом. Можно найти и использовать опыт других стран и городов по улучшению экологии, есть методы по улучшению экологии без привлечения капитала, а только выход через законодательную инициативу. Использование вторично материалов или отходов, сделает нашу жизнь благоприятней для природы, а так же поспособствует улучшению экологической обстановки.

В нашей стране и крае нет стимула к развитию инноваций. Проблема вовсе не в экологических составляющих, что грязно и нечем дышать, проблема в людях, которые не хотят принимать инновации, разбираться в проблеме и ее составляющих.

Рассмотрим, какое количество выбросов зафиксировали за 2004-2014 годы в Красноярске. Информация о выбросах наиболее распространенных загрязняющих атмосферу веществ, отходящих от стационарных источников представлена на рисунке 1.

Из рисунка 1 видно, что за это время выбросы оксида углерода и оксидов азота выросли. Источники выброса идут как предприятия, так и автотранспорт, поэтому конкретный вывод о причинах выбросов сделать нельзя. Предприятия теплоэнергетики и металлургии уменьшили выброс, об этом свидетельствует уменьшение показателя диоксида серы и твёрдых веществ. Обстановка по Красноярскому краю в 2018 году показана на рисунке 2.

Таким образом, выбросы предприятий уменьшаются, а от автотранспорта не перестают падать, это показывает, что уровень загрязнения остается неизменным. Больше загрязненного воздуха в городе не в местах базовых произ-

\begin{tabular}{|c|c|c|c|c|c|}
\hline & Твёрдые вещества & Аиоксид серы & $\begin{array}{c}\text { Оксиды азота, в } \\
\text { пересчете на NO2 }\end{array}$ & Оксид углерода & $\begin{array}{c}\text { Углеводороды, } \\
\text { включая лОС }\end{array}$ \\
\hline 2004 & 153,1 & 2111,7 & 70,2 & 161,2 & 27,9 \\
\hline 2005 & 167,6 & 2073,7 & 84,8 & 164,3 & 25,7 \\
\hline 2006 & 155,4 & 2051 & 74,1 & 146,3 & 16,2 \\
\hline 2008 & 161,9 & 2034,3 & 73,6 & 143,1 & 16,6 \\
\hline 2010 & 141,8 & 2010,3 & 96,2 & 189,9 & 25,2 \\
\hline 2012 & 140 & 2035,3 & 93,9 & 244 & 36,6 \\
\hline 2014 & 112,7 & 1894,6 & 88,9 & 201,6 & 29,2 \\
\hline
\end{tabular}

Puc. 1. Выбросы наиболее распространенных загрязняющих атмосферу веществ, отходящих от стационарных источников [3]

\begin{tabular}{|c|c|c|c|}
\hline Годы & Суммарные выбросы & Выбросы от стационарных источников & $\begin{array}{c}\text { Выбросы от передвижных } \\
\text { источников }\end{array}$ \\
\hline 2014 & 2592,0 & $2355,8^{1)}$ & $236,2^{2}$ \\
\hline 2015 & 2729,1 & $2475,9^{1)}$ & $253,2^{2)}$ \\
\hline 2016 & 2630,3 & $2363,3^{1)}$ & $267,0^{2)}$ \\
\hline 2017 & 2628,5 & $2369,5^{1)}$ & $259,0^{2}$ \\
\hline 2018 & 2613,8 & $2318,9^{3)}$ & $295,8^{3)}$ \\
\hline
\end{tabular}

Puc. 2. Динамика выбросов загрязняющих веществ в атмосферу Красноярского края с учетом выбросов Норильского промрайона, тыс. в год. 
водств, а возле дорог с загруженным трафиком. Хоть заводы виноваты в плохой экологической обстановке, машины вносят весомый вклад в текущее состояние. Нужно обращать внимание на другие источники загрязнения и не только воздуха. Конечно же вся эта ситуация с плохой экологической обстановкой и выбросами не могла не повлиять на здоровье человека. Дышать выбросами, просыпаться каждое утро и видеть за окном смог, не могут не повлиять на состояние человека. Еще в 2017 году Красноярск входил в двадцатку самых грязных городов России, а в 2018 - он возглавил этот список. Например, с 6 по 7 декабря 2018 года на сайте Среднесибирского УГМС (управление по гидрометеорологии и мониторингу окружающей среды) была размещена новость о режиме неблагоприятных метеоусловий первой степени опасности. Сведения синоптиков показали, что на территории Красноярска ожидались метеорологические условия, неблагоприятные для рассеивания вредных примесей в атмосферном воздухе. В Минусинске и Назарово так же скапливался грязный воздух, но все это было кратковременным явлением и, к счастью, режим «чёрного неба» не вводился.

А теперь хотелось бы привести сведения о заболеваниях, к которым привела данная экология края. Данные новостей Сибири, Урала и Дальнего Востока «Sibnovosti.ru» на 20 июня 2018 года сообщают, что в 2017 году число жителей Красноярского края, страдающих заболеваниями разного характера, выросло на 1,8\% по отношению к 2016-му году. Так, в больницы региона за данный период обратились 2,3 млн. человек. Приметно то, что население Красноярского края на 2017 год составило 2,8 млн. человек.

Также было сказано, что в 2017 году красноярцы обращались с жалобами, в большинстве случаев, на болезни органов дыхания. С такими симптомами к врачам попали 854 тысячи человек, что на 2,8\% больше, чем в 2016-м году.

Текущий процент растет в большом объёме, и если сейчас ничего не предпринять, то смертность в Красноярском крае будет расти. Эту проблему необходимо решить, как можно быстрее, предпринять вынужденные меры. Красноярский край имеет большую рабочую силу, и как говорил Л.Ю. Анисимов в своей статье «Итоги и перспективы развития социальной политики в Красноярском крае (к постановке проблемы)» [2] отличительным качеством социального развития любого региона является неравенство их социокультурного и социально-экономического развития, обусловленного географическими, природными, образом жизни населения, а также сложившимися историческими условиями. Красноярский край считается одним из восьми регионов-доноров, обеспечивая более 70\% товарообмена с иностранными контрагентами. Итоги и перспективы развития социальной политики в регионе определяются местом и ролью Красноярского края в мире и в России, внутри региональными особенностями взаимоотношения общества и природы.

Предлагаемые научным сообществом способы очистки, переработки и обработки мусора сводятся к следующему: ведение налога на прибыль и ведение оффшора (территория, область или страна с особыми условиями ведения бизнеса для различных компаний иностранного уровня, среди которых нулевые или очень маленькие налоги, простые правила корпоративной отчётности и управления), прибыль от которых в дальнейшем можно применять для введения субсидий и налоговых льгот для поощрения экологически чистых технологий и производства. Так же поспособствовать внедрению идей по организации раздельного сбора отходов, сокращению количества свалок и переработке мусора. Как и говорилось; некоторые пункты не нуждаются в особых затрат, они потребуют законодательную инициативу.

Дело в том, что некоторые предприятия не борются с проблемами экологии в нашем городе должным образом. Об этом свидетельствует Государственный доклад «О состоянии и охране окружающей среды в Красноярском крае» [7] за 2018 год в котором говорится, что уровень загрязнения атмосферного воздуха остается по-прежнему высоким. Причины таковы:

- рост транспорта и как следствие выхлопа от него;

- не должный контроль выбросов предприятий.

Известно как бороться со стационарными загрязнителями, но что касаемо транспортных средств, то тут нужно понимать причины, по которым люди приобретают средство передвижения

Необходимость передвигаться постоянно растет, если «постоянно», не в шаговой доступности. Как пример - детские учреждения. На работу человек может передвигаться на автобусе, но с появлением детей, необходимость в ма- 
шине возрастает. Потому что детские сады дают, где получится, без учета адреса жительства. С увеличением количества детей в семье увеличивается и число детских садов куда нужно отвезти всех детей. Выходить из этой ситуации нужно следующими способами:

- грамотно обеспечивать развитие социальной и несоциальной инфраструктуры, а так же площадки для проведения крупных мероприятий (парки, площади);

- обеспечить распределение мест в школы и детсады по необходимым адресам;

- количество мест в детских садах и школах должно быть с должным запасом. Для обеспечения беспроблемного перевода в то образовательное учреждение, куда удобно водить ребёнка (например, при переезде). Избыток мест и свободные кабинеты использовать под секции и кружки.

Необходим более развитый общественный транспорт. Метро или монорельс отлично, но начать с малого. Много человек пересели бы на автобус, но при соблюдении некоторых требований: малое время ожидания, возможность доехать без пересадок, хорошее состояние транспорта, должная стоимость. Отсюда, вытекают необходимые меры для достижения жела- емого результата:

- совершенствовать плохую схему движения маршрутов, чтобы в любую точку города можно быть добраться как минимум с одной пересадкой;

- поощрять крупный бизнес, который может обеспечить приезд работников общим служебным транспортом;

- контроль проб качество бензина на АЗС постоянно.

Все вышесказанное, говорит о том, что экология - больная тема для нашего края. На данный момент экологическая обстановка не улучшается, и причин к этому нет. Заболевания растут, а небо «чернеет». Есть масса способов улучшить данную ситуацию, главное донести ее до нужных людей в ближайшее время. Так же стоит произвести полный разбор загрязнения атмосферы в чертах города кроме транспорта и крупной промышленности, а именно котельные, бензозаправки и точечную застройку и провести все меры по их устранению всех проблем. Так же, произвести зависимость налогов от уровня загрязнения. Вполне возможно, что от крупных загрязнителей больше вреда, чем налоговых поступлений

\section{Библиографический список}

1. ТВК. В Красноярском крае уровень загрязнения воздуха остается «очень высоким» [Электронный ресурс] Режим доступа - URL: https://tvk6.ru/publications/news/35867/ (Дата обращения 21.08.2019)

2. Анисимова Л.Ю. Итоги и перспективы развития социальной политики в красноярском крае (к постановке проблемы) [Электронный ресурс] - Режим доступа - URL: https://tvk6.ru/publications/news/35867/ https://cyberleninka.ru/article/v/itogi-i-perspektivy-razvitiya-sotsialnoy-politiki-v-krasnoyarskom-krae-kpostanovke-problemy (Дата обращения 21.08.2019)

3. Выбросы наиболее распространенных загрязняющих атмосферу веществ, отходящих от стационарных источников [Электронный ресурс] - Режим доступа - URL: http://maristat.gks.ru/wps/wcm/connect/rosstat_ ts/maristat/resources/b156ce8043ab791688409cd06954faf7/\%D0\%92\%D1\%8B\%D0\%B1\%D1\%80\%D0\%BE\%D1\%8 1\%D1\%8B.htm(Дата обращения 21.08.2019)

4. Интернет газета newslab.ru.B Красноярске объявили режим «чёрного неба» [Электронный ресурс] - Режим доступа - URL: https://newslab.ru/news/870577 (Дата обращения 21.08.2019)

5. Электронный pecypc sibnovosti.ru Жители Красноярского края стали чаще страдать от болезней легких. [Электронный ресурс] - Режим доступа - URL: http://krsk.sibnovosti.ru/society/366352-zhitelikrasnoyarskogo-kraya-stali-chasche-stradat-ot-bolezney-legkih (Дата обращения 21.08.2019)

6. Дмитрий Красноярский. Ситуация с ТЭЦ и котельными Красноярска. [Электронный ресурс] - Режим доступа - URL: http://realkrsk.blogspot.com/2018/04/sgk.html (Дата обращения 21.08.2019)

7. Государственный доклад «О состоянии и охране окружающей среды в Красноярском крае» за 2018 год. [Электронный ресурс] - Режим доступа - URL: http://www.mpr.krskstate.ru/envir/page5849/0/id/39742 